\section{A bilingual advantage in controlling language interference during sentence comprehension*}

\author{
ROBERTO FILIPPI \\ Anglia Ruskin University, Cambridge \& Birkbeck, \\ University of London \\ ROBERT LEECH \\ Imperial College London \& \\ Hammersmith Hospital, London \\ MICHAEL S. C. THOMAS \\ Birkbeck, University of London \\ DAVID W. GREEN \\ University College London \\ FREDERIC DICK \\ Birkbeck, University of London
}

(Received: February 15, 2011; final revision received: November 23, 2011; accepted: May 28, 2011)

\begin{abstract}
This study compared the comprehension of syntactically simple with more complex sentences in Italian-English adult bilinguals and monolingual controls in the presence or absence of sentence-level interference. The task was to identify the agent of the sentence and we primarily examined the accuracy of response. The target sentence was signalled by the gender of the speaker, either a male or a female, and this varied over trials, where the target was spoken in a male voice the distractor was spoken in a female voice and vice versa. In contrast to other work showing a bilingual disadvantage in sentence comprehension under conditions of noise, we show that in this task, where voice permits selection of the target, adult bilingual speakers are in fact better able than their monolingual Italian peers to resist sentence-level interference when comprehension demands are high. Within bilingual speakers we also found that degree of proficiency in English correlated with the ability to resist interference for complex sentences both when the target and distractor were in Italian and when the target was in English and the distractor in Italian.
\end{abstract}

Keywords: bilingualism, inhibition, executive function, sentence interpretation, control of interference

\section{Introduction}

Bilinguals outperform monolinguals on a range of executive function tasks of a non-verbal nature (e.g., Bialystok, 1999, 2009; Bialystok, Craik, Klein \& Viswanathan, 2004; Bialystok, Craik \& Ryan, 2006; Bialystok, Martin \& Viswanathan, 2005; Carlson \& Meltzoff, 2008; Costa, Hernandez \& SebastiánGallés, 2008; Martin-Rhee \& Bialystok, 2008; Prior \& MacWhinney, 2010) even when there is a very close match in terms of cultural and developmental history (e.g., Yang, Yang \& Lust, 2011). The advantage may be attributable to the additional control demands placed on bilingual relative to monolingual speakers.

All speakers, monolingual and bilingual, must resolve competition arising within the linguistic system. In a verbal fluency task, for example, speakers must select from among different exemplars of a category. Recent research supports the view that processes used to resolve such conflict are also used to resolve conflict between other types of non-linguistic choices (e.g.,

\footnotetext{
* This study was funded by the UK ESRC grant RES-062-23-2721. Our thanks to Francesca Antichi for her assistance.
}

Snyder, Hutchinson, Nyhus, Curran, Banich, O'Reilly \& Munakata, 2010). In brief, speech production (and speech comprehension too) requires executive processes that resolve conflict. Bilinguals face additional demands on such processes. Research confirms that the languages of bilingual speakers are jointly active (e.g., Dijkstra, Van Jaarsveld \& Brinke, 1998; Van Hell \& Dijkstra 2002; Von Studnitz \& Green, 2002; Wu \& Thierry, 2010) and so use of one language means control of the other in order to avoid using words of that language inappropriately or switching into it. Bilingual speakers have to resolve language conflict perhaps through the suppression of the non-target language (Green, 1986, 1998; Hoshino \& Thierry, 2011; Linck, Kroll \& Sunderman, 2009; Macizio, Bajo \& Cruz Martin, 2010; Philipp \& Koch, 2009) or by restricting competition to words within the target language in some manner (e.g., Costa \& Caramazza, 1999; Finkbeiner, Gollan \& Caramazza, 2006; see Bialystok, Craik, Green \& Gollan, 2009 for a fuller discussion). On the supposition that language control recruits processes of cognitive control that are deployed in a range of tasks (e.g., Green, 1986, 1998), bilingualism will enhance cognitive control abilities in other domains. 
A bilingual advantage in non-verbal tasks strongly supports the idea that language control in bilinguals uses a more general control system that resolves conflict. Practically, and theoretically, it is also important to establish that bilingualism enhances conflict control when the task is a linguistic one. Early work showed that bilingual children are better able to judge the grammaticality of semantically anomalous sentences relative to their monolingual peers - they were able to suppress content in order to assess form (e.g., Bialystok, 1988). Bilinguals also showed reduced interference in the visual Stroop task (Bialystok, Craik \& Luk, 2008). Surprisingly, given that bilingual speakers must disentangle auditory messages, there is a dearth of work examining a bilingual advantage in the auditory modality. Our aim was to see if bilinguals also show an advantage relative to their monolingual peers in comprehending auditorily-presented target sentences paired with auditory distractor sentences.

Soveri, Laine, Hämäläinen and Hugdahl (2011) demonstrated a bilingual advantage in a low-level perceptual task. They used a forced-attention dichotic listening task with syllabic stimuli (Hugdahl \& Andersson, 1986). In this paradigm, pairs of syllables are presented simultaneously, one to the left and one to the right ear. Soveri and colleagues asked early FinnishSwedish bilinguals and monolingual controls to focus either on the left or the right ear (forced-left and forcedright conditions) and report the target syllable. Bilinguals outperformed Finnish monolinguals in reliably reporting more target syllables in both conditions. This finding, they argued, supported previous research, indicating that bilingualism enhances executive function, in particular in the inhibition of irrelevant information.

Do bilinguals also show an advantage when performing a higher-level speech processing task? In fact, an initial view of the literature would suggest that, to the contrary, they are at a disadvantage. This research has examined the effect of background noise and reverberation on sentence comprehension. Two studies, one by Mayo, Florentine and Buus (1997) and, the other by Shi (2010), investigated bilingual sentence comprehension in degraded acoustic conditions, using the Speech Perception in Noise paradigm (SPIN - Bilger, Nuetzel, Rabinowitz \& Rzeczkowski, 1984; Kalikow, Stevens \& Elliot, 1977). In this paradigm, participants are presented with highly predictable sentences (e.g., The doctor prescribed the $D R U G$ ) and low predictable sentences (e.g., She has known about the DRUG). The task is to identify the last word (drug in the above examples). The sentences are presented either in quiet or in noisy conditions (multi-babbler background or reverberation). In the first study, Mayo et al. (1997) showed that monolingual native speakers of English outperformed Spanish-English early bilinguals in English: they were more accurate in identifying the target word when the sentence was presented in acoustically degraded conditions. In the second study, Shi (2010) extended Mayo's and colleagues' work to sound reverberation. The author demonstrated that bilingual Korean-English listeners performed more poorly in English than monolinguals with both background noise and reverberation. Both studies are consistent with previous findings showing a bilingual disadvantage in comprehending monosyllabic words in noise (Rogers, Lister, Febo, Besing \& Abrams 2006; Tabri, Chacra \& Pring, 2011). One possible interpretation could be that bilinguals are less efficient at extracting meaning and so suffer more interference when the cues to meaning in the speech signal are degraded. In the absence of noise their performance is equivalent to that of monolingual speakers. However, neither of these studies examined sentence comprehension when the distracting information could be suppressed. Indeed this paradigm is not suited to determining a bilingual advantage in sentence processing under linguistic interference.

To investigate this question, we developed a listening paradigm in which both visual and auditory stimuli were used. Participants listened to auditory prerecorded sentences featuring two animals whose pictures appeared on a computer screen. Bilingual speakers of Italian and English, Italian monolinguals and English monolinguals, were required to identify the agent of the sentence while ignoring a competing sentence. Both target and distractor were presented simultaneously to both ears (technically, a diotic presentation). In contrast to studies examining performance under noise, the competing or distracting sentence was spoken in another voice. The voice of the speaker therefore affords a way to select the target sentence and suppress the non-target sentence.

We adapted sentences from cross-linguistic (e.g., Bates, Devescovi \& Wulfeck, 2001; MacWhinney \& Bates, 1989), clinical (Dick, Wulfeck, Aydelott, Dronkers, Gernsbacher \& Bates, 2001) and developmental research (Leech, Aydelott, Symons, Carnevale \& Dick, 2007). We contrasted performance on canonical sentences with Subject-Verb-Object (S-V-O) word order (e.g., The cat is biting the dog; It's the cat that is biting the dog) with that on non-canonical sentences with a different word order (e.g., O-V-S: The cat is bitten by the dog or O-S-V: It's the cat that the dog is biting). Prior work (e.g., Dick et al., 2001; Leech et al., 2007) established that performance is worse with non-canonical sentences particularly under conditions of noise. One reason is that the cues to meaning, and to the identity of the agent, are more transparent in canonical than in non-canonical sentences (Bates et al., 2001; MacWhinney \& Bates, 1989). In non-canonical sentences, the agent of the sentence is not in first position typical of English sentences and so any initial thematic assignment must be suppressed in favour of a noun heard later.

\section{CAMBRIDGE JUURALS}


English and Italian are both non-agglutinative languages with a basic canonical S-V-O word order (e.g., Bates, McNew, MacWhinney, Devescovi \& Smith, 1982). Thus, canonical sentences were taken to be easier with a low comprehension demand (Roland, Dick \& Elman, 2007). Conversely, the non-canonical sentences were taken to be harder with a high comprehension demand though the actual demand may differ somewhat for these two languages. Cross-linguistic studies (e.g., Bates et al., 1982) have shown that English speakers rely more on word order, whereas Italian speakers rely more on noun-verb agreement (Italian marks the verb to agree with the subject of a sentence). The Italian verb morphology is therefore more transparent and facilitates disambiguation (e.g., in English, the verb bite is the same in phrase I bite as in you bite but in Italian the verb is different io mordo and tu mordi.

The sentences presented in this study were recorded by male and female native speakers of either Italian or English. Participants were prompted to attend to sentences produced by just one speaker (the target sentences) and ignore the other sentences (the distractor sentences). The target sentences were either in the native or in the nonnative language and the distractor sentences were either in the same or in a different language to the target sentence. Participants pressed one of two buttons (see Figure 1) to indicate the agent of the target sentence. We analysed the accuracy of their responses.

We expected that in this task all groups would have comparable performance in the absence of any interfering sentence. Identifying any bilingual advantage requires a close match in terms of language and language proficiency. We therefore contrasted the performance of bilingual Italian-English speakers and monolingual Italian controls processing target and distractor sentences in Italian. We predicted that Italian-English bilinguals would show an advantage at selecting the target message in the presence of linguistic interference especially in the case of non-canonical sentences. Bilinguals, we supposed, must become adept in conversational contexts at ignoring distracting utterances whose meaning they can understand, whether in Italian or in English. As a subsidiary question we also contrasted the performance of the bilingual speakers and monolingual English controls where the target sentence was English. We made no directional prediction here because the groups might be expected to differ in their English proficiency. English monolinguals might then suffer more interference than bilingual speakers but such a difference could not be clearly attributed to enhanced cognitive control in bilingual speakers. Alternatively, if enhanced proficiency in the native language is associated with increased skill in controlling interference (e.g., Tzelgov, Henik \& Leiser, 1990), then monolingual English speakers should show reduced interference in processing distracting information in English compared to bilingual speakers with English as their second language. Given our supposition that any bilingual advantage derives from the experience of using two languages we also examined within the bilingual group the relationship between accuracy of response in the most taxing conditions (non-canonical sentences with native language interference), and proficiency in English assessed objectively with a standardised test, the Bilingual Verbal Ability Tests (BVAT - Muñoz-Sandoval, Cummins, Alvarado \& Ruef, 1998).

\section{Methods}

\section{Participants}

There were 60 healthy adults who composed three language groups: (i) twenty Italian-English bilinguals living in the UK (mean age $=32.0$ years, $\mathrm{SD}=6.3$, range $=$ 20.2-40.7; 9 males); (ii) twenty Italian monolinguals living in Italy (mean age $=32.0$ years, $\mathrm{SD}=10.0$, range $=19.4-49.7 ; 10$ males), and (iii) twenty English monolinguals living in the UK (mean age $=30.1$ years, $\mathrm{SD}=6.6$, range $=24.2-55.4 ; 8$ males). Two Italian monolingual participants could not complete all tasks and were excluded from data analysis. All participants signed an informed consent and did not report any visual, auditory or neurological impairment.

The bilingual participants completed a language history questionnaire adapted from Li, Sepanski and Zhao (2006). They received their formal education in Italy and moved to the UK later in adulthood, mainly for professional reasons. On average, their first exposure to English was after the age of ten. All bilingual participants self-rated their competence in English on four language dimensions using a scale ranging from 1 (very poor) to 6 (native-like). All reported good competence in English on all dimensions, with a 4.9 mean score for reading ability $(\mathrm{SD}=0.7), 4.5$ for writing ability $(\mathrm{SD}=0.9), 4.4$ for speaking ability $(\mathrm{SD}=0.9)$, and 4.5 for listening ability $(\mathrm{SD}=0.9)$. On this basis, they were all admitted to take part in the study. Thirteen of them reported being exposed to a third or a fourth language but only six participants rated themselves as fluent in three languages and one in four languages. The majority of bilingual speakers $(87 \%)$ reported switching between their languages during conversation.

The Italian monolingual participants were all from Livorno, a town located on the Italian West coast in Tuscany, a region in Italy in which the local population does not speak any dialect. The language in use is therefore Italian, although there are subtle regional inflections. All Italian monolinguals were exposed to English in their adolescence as English was taught as a second language in secondary school. However, none of them reported a

\section{CAMBridge JDURNALS}


Table 1. Summary of biographical information, audio-motor task and Raven's Matrices.

\begin{tabular}{|c|c|c|c|c|c|c|c|c|c|}
\hline \multirow[b]{2}{*}{$\begin{array}{l}\text { Language } \\
\text { group }\end{array}$} & \multirow[b]{2}{*}{$\mathrm{N}$} & \multirow[b]{2}{*}{$\begin{array}{l}\text { Age } \\
(\mathrm{SD})\end{array}$} & \multirow[b]{2}{*}{$\begin{array}{l}\text { Sex } \\
(M / F)\end{array}$} & \multirow[b]{2}{*}{$\begin{array}{l}\text { Years of } \\
\text { education (SD) }\end{array}$} & \multicolumn{4}{|c|}{ Audiometric task } & \multirow[b]{2}{*}{$\begin{array}{l}\text { Raven's } \\
\% \text { CR (SD) }\end{array}$} \\
\hline & & & & & $\begin{array}{l}\text { Left ear } \\
\text { RT ms (SD) }\end{array}$ & $\begin{array}{l}\text { Right ear } \\
\text { RT ms (SD) }\end{array}$ & $\begin{array}{l}\text { Left ear } \\
\% \text { CR (SD) }\end{array}$ & $\begin{array}{l}\text { Right ear } \\
\% \text { CR (SD) }\end{array}$ & \\
\hline Bilinguals & 20 & $\begin{array}{l}32.0 \\
(6.3)\end{array}$ & $9 / 11$ & $\begin{array}{l}18.6 \\
(2.9)\end{array}$ & $\begin{array}{l}370 \\
(70)\end{array}$ & $\begin{array}{l}370 \\
(70)\end{array}$ & $\begin{array}{l}99.0 \\
(2)\end{array}$ & $\begin{array}{l}100 \\
(0)\end{array}$ & $\begin{array}{l}61.2 \\
(10.0)\end{array}$ \\
\hline $\begin{array}{l}\text { Italian } \\
\text { monolinguals }\end{array}$ & 20 & $\begin{array}{l}32.0 \\
(10.0)\end{array}$ & $10 / 10$ & $\begin{array}{l}18.7 \\
(3.2)\end{array}$ & $\begin{array}{l}370 \\
(90)\end{array}$ & $\begin{array}{l}370 \\
(90)\end{array}$ & $\begin{array}{l}99.7 \\
(1)\end{array}$ & $\begin{array}{l}98 \\
(3)\end{array}$ & $\begin{array}{l}61.5 \\
(6.6)\end{array}$ \\
\hline $\begin{array}{l}\text { English } \\
\text { monolinguals }\end{array}$ & 20 & $\begin{array}{l}30.1 \\
(6.6)\end{array}$ & $8 / 12$ & $\begin{array}{l}17.0 \\
(1.8)\end{array}$ & $\begin{array}{l}340 \\
(10)\end{array}$ & $\begin{array}{l}340 \\
(10)\end{array}$ & $\begin{array}{l}93.0 \\
(2)\end{array}$ & $\begin{array}{l}93 \\
(2)\end{array}$ & $\begin{array}{l}62.3 \\
(11.0)\end{array}$ \\
\hline
\end{tabular}

daily use of English. English monolinguals did not report any exposure to Italian.

Biographical information and performance on background tests are summarised in Table 1.

\section{Tasks and procedure}

Participants were tested twice in a quiet room by the same experimenter on the same equipment. They were administered five tasks in total: (i) the sentence interpretation task with interference; (ii) the sentence interpretation task without interference (baseline); (iii) an auditory-motor task; and (iv) an online version of the Raven's Matrices test. The bilingual participants' proficiency in English was assessed with a standardised test, the Bilingual Verbal Ability Tests (BVAT - MuñozSandoval et al., 1998). All tasks were counterbalanced across each experimental session. Bilinguals and English monolinguals were tested in the UK, Italian monolinguals in Italy.

Each session started with an auditory-motor task (Leech et al., 2007) to establish if the participants could successfully perform an auditory task presented to either ear. This baseline measure consisted of 32 'ping' sounds, each 0.3 seconds long, adapted from the alert sounds native to Mac OS 10.3. Participants pressed either the left or the right button on a response keypad corresponding to the ear in which they heard a sound. Participants were asked to press the button as fast as they could with the thumbs of both hands.

\section{Sentence interpretation task}

\section{Stimuli}

Ninety-six English sentences were adapted from Leech et al. (2007) and translated into Italian. Both sets were digitally recorded. The English sentences were spoken by native English speakers and the Italian sentences by native Italian speakers to form a total of 192 auditory stimuli. The sentences were equally distributed between canonical (i.e., Subject-Verb-Object) and non-canonical (i.e., ObjectVerb-Subject/Object-Subject-Verb) syntactic structures. Each sentence described an action between two familiar animals, one serving as the subject and the other as the object (e.g., The bull is biting the cat, The cat is bitten by the bull). More example sentences are shown in Table 2. A complete list of sentences is provided in the appendix.

The sentences were associated with visual stimuli, i.e., computerised black-and-white line drawings of animals taken from Abbate and LaChappelle (1984a, b) and Snodgrass and Vanderwart (1980) databases. The animaldenoting nouns were not interlingual cognates. Each animal drawing sized $7.0 \mathrm{~cm}$ by $5.0 \mathrm{~cm}$, and was embedded in a solid grey rectangle surrounded by a white background. Visual stimuli were displayed in pairs, one on the left-hand side and one on the right-hand side of a computer screen (but never the same animal on both sides) and associated with the relevant sentence.

The target sentence was always associated with the visual stimuli featuring the two animals in the sentence. The interfering sentence was always spoken by a speaker of the opposite gender (i.e., Target $=$ male voice, Interference $=$ female voice and vice versa), never featured the same animals as the target sentence, and always had a different syntactic structure (i.e., Target $=$ canonical, Interference $=$ non-canonical and vice versa). The sentences were constructed in such a way that each animal appeared twice as subject and twice as object. A given action verb was associated only once with a given paring of a subject and object noun. The test verbs had a mild negative meaning serving to identify the animal "doing the bad action".

Four pseudo-random presentation orders were created and were randomly allocated to five participants in each linguistic group. Each presentation consisted of 192 items split into two parts: the first part contained 96 sentences spoken by a male (48 in English and 48 in Italian) and the second part 96 sentences spoken by a 
Table 2. Example of sentence types (the agent is in bold).

\begin{tabular}{lllll}
\hline \hline Sentence type & Constituent order & English & Italian & $\begin{array}{c}\text { No. of sentences } \\
\text { per language }\end{array}$ \\
\hline Canonical & $\begin{array}{l}\text { Active (S-V-O) } \\
\text { Subject cleft } \\
(\mathrm{S}-\mathrm{V}-\mathrm{O})\end{array}$ & $\begin{array}{c}\text { The whale is pushing the frog } \\
\text { It’s the seal that is pushing the } \\
\text { cow }\end{array}$ & $\begin{array}{c}\text { La balena spinge la rana } \\
\text { È la foca che spinge la mucca }\end{array}$ & 24 \\
Non-canonical & $\begin{array}{c}\text { Passive (O-V-S) } \\
\text { The whale is pushed by the } \\
\text { seal }\end{array}$ & La balena è spinta dalla foca & 24 \\
& $\begin{array}{c}\text { Object cleft } \\
(\mathrm{O}-\mathrm{S}-\mathrm{V})\end{array}$ & $\begin{array}{c}\text { It's the monkey that the cow is } \\
\text { pushing }\end{array}$ & $\begin{array}{c}\text { È la scimmia che la mucca } \\
\text { spinge }\end{array}$ & 24 \\
\hline \hline
\end{tabular}

female (48 in English and 48 in Italian). Therefore, it took two presentations (two participants) to administer all the sentences. Two other presentations allowed the gender of the target voice to be also counterbalanced. The target items were pseudo-randomly allocated in short runs and associated with items used as interference. Pseudorandomisation allowed to include all possible conditions in each run, that is: target canonical sentences associated with non-canonical sentence either in L1 or L2, and non-canonical sentences associated with canonical ones either in L1 and L2. In the control condition without interference, only the target sentences were used in the same presentation orders. All sentences were used either as targets in Italian and English or as linguistic distractors in the interference condition. They were fully counterbalanced in a way that each participant was exposed to an equal number of same language (i.e., Italian (ITA)/Italian (ITA), English (ENG)/English (ENG) or different language trials (i.e., ITA/ENG, ENG/ITA). Sentences were recorded in a sound-proof booth by native speakers of British English or Italian, two females and two males. Using Digidesign MBox, a Macintosh G4 and ProTools LE software, all recorded stimuli were digitised at a sampling rate of $44.125 \mathrm{kHz}$ with a 16-bit quantisation. Sentences were then edited and converted into a 16-bit 44.125 kHz mono sound file in Audacity 1.2.5 for Mac, and saved in .wav format. Finally, all sentences were normalised to a root mean squared amplitude of 70 dB using Praat software (Boersma \& Weenink, 2010).

\section{Procedure}

In the experimental condition with language interference, participants were told that they would see two drawings of animals presented simultaneously on a computer screen, one on their right- and one on their left-hand side. They would also listen to a sentence featuring the two animals. They were required to identify the animal doing the bad action. They were also told to ignore the

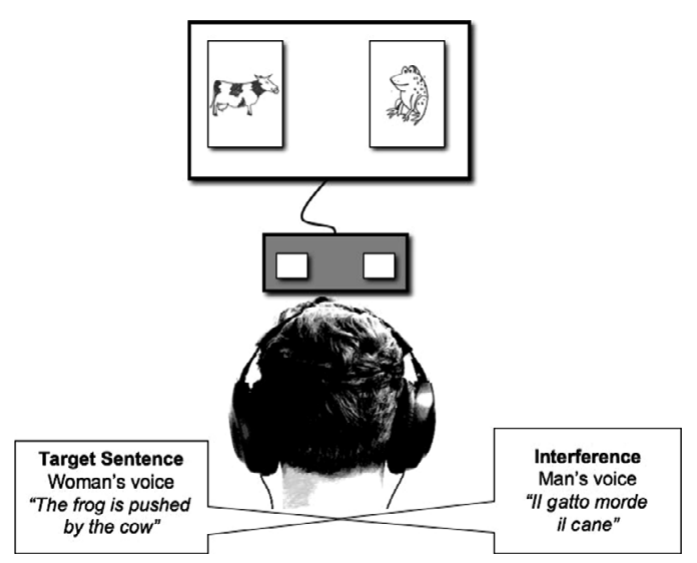

Figure 1. An illustration of the sentence interpretation task set-up. The participant is instructed to focus on the woman's voice (Target Sentence) and ignore the man (Interference). The target sentence and interference speech are simultaneously presented in both ears. The target sentence stimulus is associated with two animals featured on a computer screen. The participant is asked to identify the agent of the sentence (i.e., the animal doing the "bad action") by pressing the button on the keypad relative to the position of the animal on the screen, the cow in this case (left button).

other person talking simultaneously (always a different gender) and focus on the voice indicated on the computer screen at the beginning of the task (male or female). In the control condition without language interference, participants were told to focus on the voice and identify the animal doing the bad action. Figure 1 illustrates the experimental set-up.

To minimise learning effects, participants first performed the experimental condition with language interference and subsequently carried out the control condition without language interference. The nointerference condition was tested at a different time, with a mean temporal gap of 53.3 days. Given they were

\section{CAMBridge JDURALS}


adult participants, whose personal circumstances did not change radically between test sessions, it was assumed that their language dominance would be relatively stable over a two-month period.

Bilinguals were instructed in English. All participants completed 16 practice trial sentences for each experimental condition. The side of presentation of the subject animal (left or right) was counterbalanced across participants. The task was presented in short runs of 4 , 6 , or 8 trials each. In order to maximise interference and therefore the need for selective attention, a run with target sentences in English was always followed by a run with target sentences in Italian and vice versa. The trials appeared automatically after the participants' response. If, they gave no response, the next trial was presented after three seconds. All language groups carried out the same task. Monolinguals were told to focus on, and respond to, the target sentences in their native language. When the target sentences were not in their native language, monolingual participants were asked to guess.

The experiment was administered on the same equipment to all participants: a MacBook 13-inch laptop computer using Matlab 7.7.0 (Mathworks Inc. Sherbon MA, USA), Sennheiser EH-150 headphones, and USB Logitech Precision game-pad to record the participants' response accuracy.

\section{Raven's Matrices}

All participants performed an online version of the Raven's Matrices (Raven, 1947). In this test, participants are shown an incomplete matrix of black-and-white abstract figures, with each matrix consisting of nine cells. Participants are required to select the most appropriate pattern to complete the matrix from eight potential tiles by pointing to the number of the tile that best completes the matrix. The obtained scores indicate a close match across the three groups in terms of intellectual ability.

\section{Language background questionnaire}

Bilingual participants completed a language history questionnaire adapted from Li et al. (2006). Biographical information, language use and self-proficiency assessment in L2 were collected.

\section{L2 proficiency: BVAT}

The bilinguals' degree of proficiency in English was measured with a standardised test, the Bilingual Verbal Ability Tests (BVAT - Muñoz-Sandoval et al., 1998).

The BVAT contains three tests: (i) Picture Vocabulary, in which participants are asked to name a total of 58 pictures of concrete objects of increased difficulty; (ii)
Oral Vocabulary, in which participants are presented with 44 words and required to make 20 synonymous and 24 antonymous associations; and (iii) Verbal Analogies, in which participants are asked to find 35 analogous relationships between two words and a third word (e.g., "mother is to father as sister is to... brother"). All tests are administered in English first. Each item failed in English was re-administered in the native language. The Scoring and Reporting Program software, which is a standard feature of the BVAT kit, generates a measure to assess the Cognitive-Academic Level of Proficiency in English (CALP) according to five levels and increasing in units of 0.5 in order to obtain nine degrees of cognitiveacademic proficiency in English, ranging from negligible $($ score $=1)$ to advanced $($ score $=5)$.

\section{Results}

We first report the results of the baseline task and the Raven's Matrices online task. We then report those of the sentence interpretation task focusing on the key contrast between bilingual Italian-English and monolingual Italian speakers. In a final section we examine the association between English proficiency and performance in the sentence interpretation task.

\section{Baseline auditory-motor task and Raven's Matrices}

Analysis of performance in the baseline auditory-motor task with the factors of group (bilingual, monolingual) and gender (male, female) showed no significant effects. Bilinguals and monolinguals responded equally quickly, $F(1,57)<1$ (median $\mathrm{RT}=370 \mathrm{~ms}(\mathrm{SD}=60)$ and $360 \mathrm{~ms}$, $(\mathrm{SD}=80)$ for bilinguals and monolinguals, respectively) and did not differ significantly in accuracy, $F(1,57)=$ $3.20, p=.079$ (mean proportion correct $=0.99(\mathrm{SD}=$ $0.11)$ and $0.98(\mathrm{SD}=0.02)$ for bilingual and monolingual speakers, respectively). There was no gender difference in performing the task (median RT and accuracy, $F<$ 1 in both cases). In short if differences emerged in the sentence interpretation task, they cannot be attributed to the auditory-motor aspects of the task. All groups had comparable IQ $(F<1)$.

\section{Sentence interpretation task}

An initial analysis of mean accuracy and individual median reaction time for target sentences indicated no main effect nor interactions for speaker gender $(F<1)$, and so analyses were collapsed over this factor. Analysis of the monolingual participants' level of accuracy when comprehending sentences in the unknown language revealed, as expected, that their performance was at chance $\left(F_{\mathrm{S}}<1\right)$. All groups' means for accuracy and reaction time are reported in Table 3 and illustrated in Figure 3.

\section{CAMBRIDGE JOURNALS}


Table 3. (A) Means and standard deviations for accuracy (in percentage) and response time (in milliseconds) when the groups comprehended target non-canonical sentences in the presence or absence of language interference. (B) Means and standard deviations for accuracy (in percentage) and response time (in milliseconds) when the groups comprehended target canonical sentences in the presence or absence of language interference.

\begin{tabular}{|c|c|c|c|c|c|c|}
\hline \multirow{2}{*}{$\begin{array}{l}\text { (A) } \\
\text { Group }\end{array}$} & \multicolumn{2}{|c|}{$\begin{array}{c}\text { No } \\
\text { interference }\end{array}$} & \multicolumn{2}{|c|}{$\begin{array}{c}\text { English } \\
\text { interference }\end{array}$} & \multicolumn{2}{|c|}{$\begin{array}{c}\text { Italian } \\
\text { interference }\end{array}$} \\
\hline & $\begin{array}{l}\mathrm{CR} \\
(\mathrm{SD})\end{array}$ & $\begin{array}{l}\text { RT } \\
\text { (SD) }\end{array}$ & $\begin{array}{l}\mathrm{CR} \\
(\mathrm{SD})\end{array}$ & $\begin{array}{l}\text { RT } \\
\text { (SD) }\end{array}$ & $\begin{array}{l}\mathrm{CR} \\
(\mathrm{SD})\end{array}$ & $\begin{array}{l}\text { RT } \\
(\mathrm{SD})\end{array}$ \\
\hline Bilinguals (performing in English) & $\begin{array}{l}94 \\
(8)\end{array}$ & $\begin{array}{l}2010 \\
(213)\end{array}$ & $\begin{array}{l}88 \\
(11)\end{array}$ & $\begin{array}{l}2264 \\
(245)\end{array}$ & $\begin{array}{l}94 \\
(12)\end{array}$ & $\begin{array}{l}2261 \\
(236)\end{array}$ \\
\hline English monolinguals & $\begin{array}{l}95 \\
(6)\end{array}$ & $\begin{array}{l}1979 \\
(284)\end{array}$ & $\begin{array}{l}85 \\
(16)\end{array}$ & $\begin{array}{l}2173 \\
(358)\end{array}$ & $\begin{array}{l}90 \\
(12)\end{array}$ & $\begin{array}{l}2201 \\
(380)\end{array}$ \\
\hline Bilinguals (performing in Italian) & $\begin{array}{l}96 \\
(5)\end{array}$ & $\begin{array}{l}2063 \\
(271)\end{array}$ & $\begin{array}{l}91 \\
(12)\end{array}$ & $\begin{array}{l}2262 \\
(270)\end{array}$ & $\begin{array}{l}91 \\
(10)\end{array}$ & $\begin{array}{l}2335 \\
(229)\end{array}$ \\
\hline Italian monolinguals & $\begin{array}{l}91 \\
(10)\end{array}$ & $\begin{array}{l}2150 \\
(200)\end{array}$ & $\begin{array}{l}84 \\
(17)\end{array}$ & $\begin{array}{l}2246 \\
(271)\end{array}$ & $\begin{array}{l}76 \\
(15)\end{array}$ & $\begin{array}{l}2285 \\
(263)\end{array}$ \\
\hline \multirow[t]{2}{*}{ (B) } & \multicolumn{2}{|c|}{$\begin{array}{c}\text { No } \\
\text { interference }\end{array}$} & \multicolumn{2}{|c|}{$\begin{array}{c}\text { English } \\
\text { interference }\end{array}$} & \multicolumn{2}{|c|}{$\begin{array}{c}\text { Italian } \\
\text { interference }\end{array}$} \\
\hline & $\begin{array}{l}\mathrm{CR} \\
(\mathrm{SD})\end{array}$ & $\begin{array}{l}\text { RT } \\
\text { (SD) }\end{array}$ & $\begin{array}{l}\mathrm{CR} \\
(\mathrm{SD})\end{array}$ & $\begin{array}{l}\text { RT } \\
(\mathrm{SD})\end{array}$ & $\begin{array}{l}\mathrm{CR} \\
(\mathrm{SD})\end{array}$ & $\begin{array}{l}\mathrm{RT} \\
(\mathrm{SD})\end{array}$ \\
\hline Bilinguals (performing in English) & $\begin{array}{l}97 \\
(3)\end{array}$ & $\begin{array}{l}1948 \\
(245)\end{array}$ & $\begin{array}{l}93 \\
(9)\end{array}$ & $\begin{array}{l}2238 \\
(241)\end{array}$ & $\begin{array}{l}94 \\
(9)\end{array}$ & $\begin{array}{l}2215 \\
(228)\end{array}$ \\
\hline English monolinguals & $\begin{array}{l}98 \\
(6)\end{array}$ & $\begin{array}{l}1832 \\
(163)\end{array}$ & $\begin{array}{l}92 \\
(15)\end{array}$ & $\begin{array}{l}2062 \\
(294)\end{array}$ & $\begin{array}{l}98 \\
(3)\end{array}$ & $\begin{array}{l}1998 \\
(283)\end{array}$ \\
\hline Bilinguals (performing in Italian) & $\begin{array}{l}98 \\
(3)\end{array}$ & $\begin{array}{l}1821 \\
(256)\end{array}$ & $\begin{array}{l}95 \\
(5)\end{array}$ & $\begin{array}{l}2039 \\
(244)\end{array}$ & $\begin{array}{l}96 \\
(6)\end{array}$ & $\begin{array}{l}2107 \\
(231)\end{array}$ \\
\hline Italian monolinguals & $\begin{array}{l}99 \\
(1)\end{array}$ & $\begin{array}{l}1873 \\
(154)\end{array}$ & $\begin{array}{l}96 \\
(8)\end{array}$ & $\begin{array}{l}2023 \\
(225)\end{array}$ & $\begin{array}{l}93 \\
(8)\end{array}$ & $\begin{array}{l}2086 \\
(294)\end{array}$ \\
\hline
\end{tabular}

We first discuss the accuracy data where the target sentence is Italian.

\section{Italian-English bilinguals relative to Italian monolinguals}

We first analysed the accuracy data first of all in a mixedfactor omnibus $(2 \times 2 \times 3)$ ANOVA with the betweensubjects factor of group (bilingual, monolingual) and the within-subjects factors of sentence type (canonical, noncanonical) and language interference (no interference; Italian vs. English). The mean accuracy for these two groups is shown in Figure 2a. The ANOVA revealed a significant main effect of group, $F(1,36)=5.18, p=$ $.029, \eta^{2}=.126$, with bilinguals better overall; an effect of sentence type, $F(1,36)=27.54, p<.001, \eta^{2}=$ .433 , with better performance on canonical compared to non-canonical sentences; and a significant main effect of interference, $F(2,72)=20.97, p<.001, \eta^{2}=.368$, with better performance in the absence of linguistic distractors. These main effects were qualified by a significant interaction between sentence type and group, $F(1,36)=$ 7.23, $p=.011, \eta^{2}=.167$, with bilinguals performing better than monolinguals when comprehending noncanonical sentences, and between sentence type and interference, $F(2,72)=8.30, p<.001, \eta^{2}=.187$, indicating that sentence distractors differentially affected canonical and non-canonical sentences. The third-order interaction of interference, sentence type and group was also marginally significant, $F(2,72)=2.97, p=.058$, $\eta^{2}=.076$. There was a comparable effect of non-native interference on canonical sentences in each language group but the effect of native interference on native non-canonical sentences was reduced in the bilingual group.

In order to examine the bilingual advantage specifically we contrasted the performance of the

\section{CAMBRIDGE JOURNALS}


bilingual and monolingual group when target and distractor sentences were in Italian. There was a significant three-way interaction between interference (no interference vs. native interference), sentence type (canonical vs. non-canonical) and group (bilinguals vs. Italian monolinguals), $F(1,36)=7.31, p=.01, \eta^{2}=$ .17. Bonferroni corrected $t$-tests revealed no significant differences between groups for canonical sentences either in the presence or absence of language interference. For non-canonical sentences, there were no significant differences when the task was performed without interference or with L2 interference. However, bilinguals were significantly more accurate under L1 interference than their monolingual peers in the comprehension of non-canonical sentences, $t(36)=3.49, p=.001$.

These results indicate that when the comprehension demand is high bilinguals are much better at resisting interference from their mother tongue than their monolingual peers. It is noteworthy that their performance remains relatively better than their monolingual peers even when the interfering language is English. For the bilinguals the language of the interfering sentence appears irrelevant as if at a slight cost, relative to the nointerference condition, they were able to gate it out.

\section{Italian-English bilinguals relative to English monolinguals}

Figure $2 \mathrm{~b}$ displays accuracy where the target language is English and the monolinguals are native English speakers. An omnibus $2 \times 2 \times 3$ mixed ANOVA with the betweensubjects factor of language group (bilinguals vs. English monolingual) and the within-subjects factor of sentence type (canonical, non-canonical) and language interference (no interference; Italian vs. English) showed that the two groups had comparable performance, $F(1,38)<$ 1 , but confirmed a significant main effect of sentence type, $F(1,38)=32.81, p<.001, \eta^{2}=.463$, and of interference, $F(2,76)=12.59, p<.001, \eta^{2}=.249$. The interaction between sentence type and interference was also significant, $F(2,76)=3.62, p=.031, \eta^{2}=$ .087 , indicating a greater effect of interference on noncanonical sentences. There were no other significant interactions, all $F \mathrm{~s}<1$.

In this case, the bilingual group showed no advantage over the monolingual group in response to interference with non-canonical sentences but nor, as might be expected, did they show a disadvantage.

We consider the possibility that the monolingual groups differed in their response to interference.

\section{Control of interference between the two monolingual groups}

We have found a bilingual advantage for bilingual ItalianEnglish speakers relative to their monolingual peers but
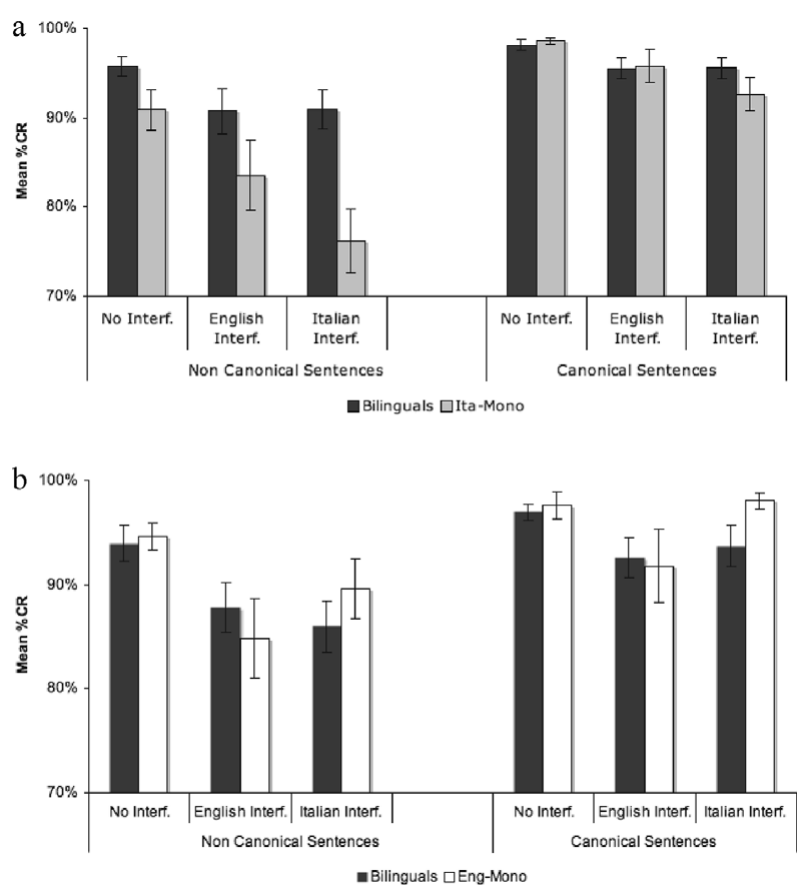

Figure 2. Comprehension of target sentences.

(a) Comprehension of Italian target sentences: bilinguals and Italian monolinguals' percent correct responses (CR) for non-canonical and canonical sentences in the presence or absence of non-native and native language interference. (b) Comprehension of English target sentences: bilinguals and English monolinguals' percent correct responses for non-canonical and canonical sentences in the presence or absence of non-native and native language interference. Error bars show standard errors.

no such advantage (but no disadvantage either) relative to English monolinguals. Conceivably, our key finding was caused by an artifact of unmatched monolingual groups. For convenience, Figure 3 displays accuracy as a function of interference for the two monolingual groups with noncanonical target sentences in the presence or absence of native and non-native language interference. We carried out a $2 \times 3$ mixed ANOVA on these data with group (English monolinguals vs. Italian monolinguals) as the between-subjects factor and interference (no interference, native interference and non-native interference) as the within-subjects variable. This indicated that, although the English monolingual group's performance was somewhat higher in accuracy overall, there was no significant difference between the two monolingual groups, $F(1,36)=2.81, p=.103, \eta^{2}=.072$. Language interference produced a significant decrease from baseline in both groups, $F(2,72)=19.57, p<.001, \eta^{2}=.352$. Critically, there was no significant interaction between group and interference, $F(2,72)<1$. The performance of the two monolingual groups was affected in the same way: English and Italian monolinguals were more 


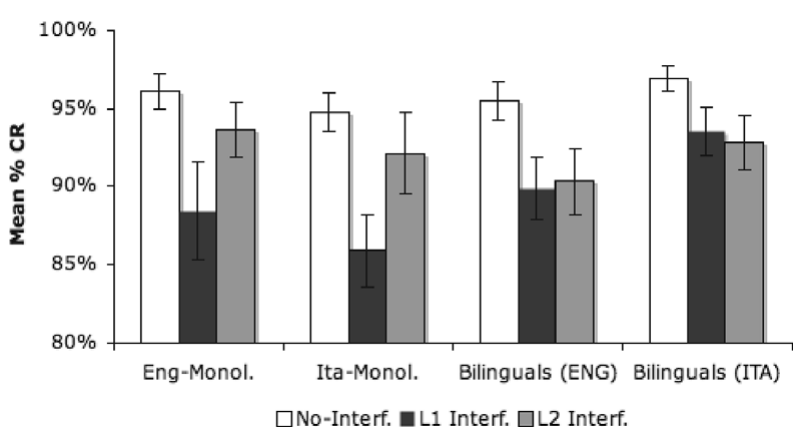

Figure 3. Monolingual and bilingual participants' overall accuracy (CR) in comprehending target sentences either in English (ENG) or in Italian (ITA) in the presence and absence of native and non-native language interference. Error bars show standard errors.

affected by native language interference than by nonnative interference when comprehending non-canonical sentences.

We conclude that the bilingual advantage observed relative to monolingual Italian peers is not artifactual.

\section{Reaction time analyses}

Given the homogeneity of the two groups in the key contrast, that is, Italian-English bilinguals compared to Italian monolinguals, we did not expect response times in sentence processing to be a particularly sensitive measure. However, they were collected and analysed to rule out any obvious trade-off. Following the same criteria for the accuracy of data as those described above, we first report the results of the Italian-English bilinguals relative to Italian monolinguals. The ANOVA revealed that both groups were significantly slower at processing sentences with interference compared to the control condition without interference, and at processing non-canonical sentences versus canonical sentences, $F(2,72)=25.91$, $p<.001, \eta^{2}=.42, F(1,36)=168.60, p<.001, \eta^{2}=$ .82 , respectively. As expected, there was no significant main effect of group, $F<1$, and no significant two-way or three-way interactions $(F \mathrm{~S}<1)$. Italian-English bilinguals and Italian monolinguals did not show any significant difference in the speed of processing the sentences or in reaching their decision. These results are illustrated in Figure 4a.

We then compared the performance of the bilinguals with the English monolinguals. The ANOVA again revealed a significant main effect of interference, $F(2,76)=$ $25.19, p<.001, \eta^{2}=.40$, with both groups slower when comprehending sentences in the presence of interference than without; and an effect of sentence type, $F(1,38)=19.53, p<.001, \eta^{2}=.34$, with faster responses to canonical compared to non-canonical sentences. Although there was no significant difference
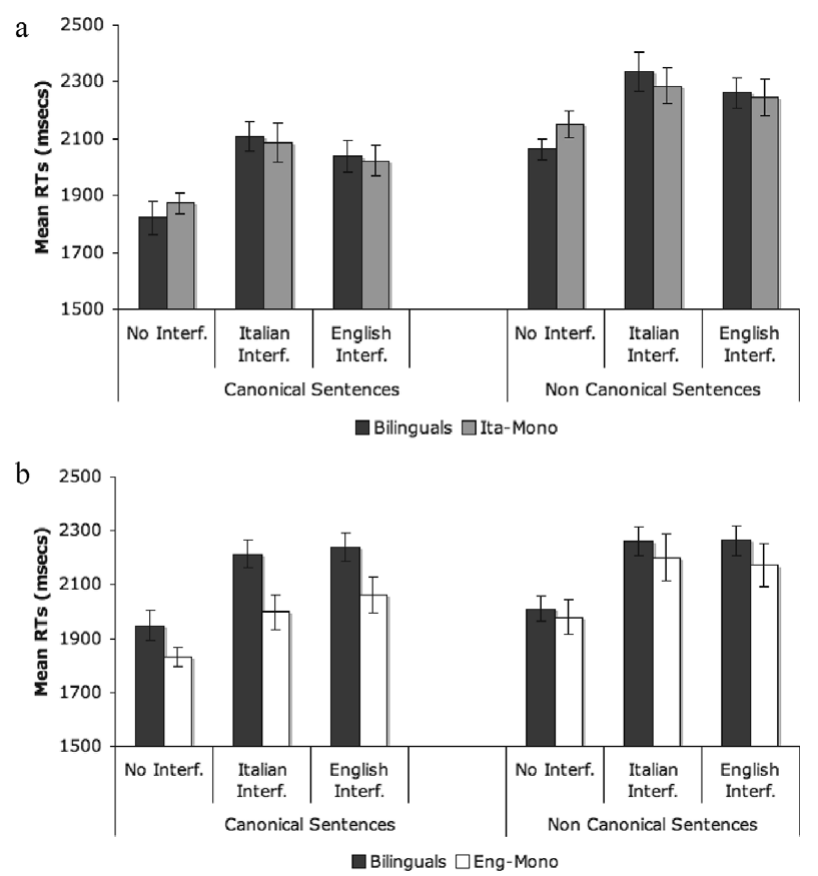

Figure 4. RT analyses. (a) Comprehension of Italian target sentences: bilinguals and Italian monolinguals' response times for non-canonical and canonical sentences in the presence or absence of non-native and native language interference. (b) Comprehension of English target sentences: bilinguals and English monolinguals' response times for non-canonical and canonical sentences in the presence or absence of non-native and native language interference. Error bars show standard errors.

in overall RT between the two groups, $F(1,38)=2.90$, $p=.010, \eta^{2}=.07, n . s$. , there was a significant interaction between sentence type and group, $F(1,38)=5.83, p=$ $.02, \eta^{2}=.13$. As illustrated in Figure $4 \mathrm{~b}$, the bilingual group appeared to be slower than English monolinguals in comprehending canonical English sentences in the presence of Italian (L1) or English (L2) interference, but equally fast in the absence of interference. However, only the difference in the Italian interference condition survived the Bonferroni corrected $t$-test, $t(38)=2.66$, $p=.011$. There was no significant difference between the two groups in the speed of processing non-canonical sentences whether in the presence or in the absence of interference. In this case, all $t$-tests were non-significant.

Finally, both monolingual groups were compared. ANOVA confirmed the main effect of interference and canonicity, $F(2,72)=13.861, p<.001, \eta^{2}=.278$; $F(1,36)=67.883, p<.001, \eta^{2}=.653$, respectively; but both monolingual groups had comparable performance $F(1,38)=2.904, p=.097, \eta^{2}=.071$, and all interactions were non-significant $(F \mathrm{~s}<1)$.

In summary, the RT analysis did not indicate any obvious speed/accuracy trade-off in the key contrast: Italian-English bilinguals' and Italian monolinguals' 
speed of processing was equally affected by language interference and grammatical complexity. The same pattern of behaviour was observed when the two monolingual groups were compared. Not surprisingly, when the bilingual participants were compared with the English monolingual controls, they appeared to be slower than native speakers when processing canonical sentences imposing a low cognitive demand in the face of native interference. However, somewhat surprisingly, they were equally fast when processing more non-canonical sentences imposing a high cognitive demand either in the presence or in the absence of native or non-native interference. ${ }^{1}$

\section{Individual differences: Control of interference and levels of proficiency in the second language}

Any advantage of our bilingual speakers relative to monolingual English speakers may be associated with the extent to which speakers have had to exercise control in using two languages. We took relative proficiency in English (assessed by the BVAT) as a proxy for such experience and examined the extent to which this predicted performance in conditions that maximise interference: English non-canonical sentences with Italian interference and Italian non-canonical sentences with Italian interference.

Participants' raw scores were computed using the Scoring and Reporting Program for the BVAT. This provides the Cognitive-Academic Level of Proficiency in English (CALP) for each participant. The number of participants at each level of proficiency was: $\mathrm{N}=3$, very limited $($ CALP score $=2.0) ; \mathrm{N}=4$, limited (CALP score $=$ 3.0 ); $\mathrm{N}=6$, limited to fluent (CALP score $=3.5$ ); $\mathrm{N}=$ 4 , fluent (CALP score $=4.0$ ); $\mathrm{N}=3$, advanced (CALP score $=5.0)$. We used the CALP score, together with a measure of IQ from Raven's Matrices, to predict accuracy in the two conditions of interest. The correlation between CALP and IQ was non-significant, $(r=.251, p=.286)$. Additionally, the CALP score was regressed against the control conditions without interference, which indicated that proficiency was a significant predictor of performance in $\mathrm{L} 2(F(1,19)=12.76, p=.002)$, but not in $\mathrm{L} 1(p>.05)$.

1 An item analysis was carried out on the subset of target sentences with interfering sentences that were direct translation equivalents over English and Italian (about $55 \%$ of the trials in all conditions). Item analyses for accuracy and response times confirmed the findings of the subject analyses already reported in the above sections. In the key contrast between the bilinguals and the Italian monolinguals, bilinguals were significantly more accurate on non-canonical items than canonical ones $(p<.001)$; they made significantly fewer errors when sentences were presented with interference $(p<.001)$, but no difference was observed in the absence of interference $(p>$ $.05)$ Item analysis on response times showed that the two groups' performance was comparable in the speed of processing sentences with interference $(p>.05)$, but bilinguals were significantly faster than Italian monolinguals in the absence of interference $(p<.001)$.
The overall multiple regression was significant in both conditions: with English non-canonical sentences and Italian interference, $F(2,19)=5.75, p=.012$, adjusted $\mathrm{R}$ square $=0.33$ and with Italian non-canonical sentences and Italian interference, $F(2,19)=4.21, p=$ .037 , adjusted $\mathrm{R}$ square $=0.24$. In both analyses, higher English proficiency was a significant predictor of better performance, Beta $=0.65, p=.004$; Beta $=0.56, p=$ .014 , respectively, and IQ was not $(t<1)$.

In the two other experimental conditions, that is, English target sentences with English interference and Italian target sentences with English interference, the degree of proficiency was also a significant predictor of accuracy, Beta $=0.60, p=.008$; Beta $=0.56, p=.016$, respectively, whereas IQ was not $(t<1)$.

These data indicate a close relationship within our bilingual sample between proficiency in their second language and the ability to control interference in both languages. The greater the bilingual proficiency, the better able bilinguals were to screen out competing, task irrelevant, L1 speech.

\section{Discussion}

In this study we investigated whether there is a bilingual advantage in sentence comprehension in the face of sentence-level interference. For this purpose we adapted a listening paradigm borrowed from cross-linguistic (e.g., Bates et al., 2001; MacWhinney \& Bates, 1989), clinical (Dick et al., 2001) and developmental research (Leech et al., 2007). Participants identified the agent of syntactically canonical and non-canonical sentences in the presence or absence of native and non-native interfering sentences. We compared the performance of ItalianEnglish adult bilinguals with a group of age-matched Italian and English monolingual controls.

In the key contrast, we confirmed a bilingual advantage. Bilingual speakers outperformed their monolingual Italian peers when responding to non-canonical Italian sentences (high comprehension demand) in the face of interfering Italian sentences. The response time analysis showed that there was no significant difference between the two groups in the speed of reaching a decision to identify the agent. Unlike the monolingual groups, the bilingual group responded equivalently when interfering sentences were presented either in Italian (native tongue) or in English (non-native). By contrast, replicating earlier data, monolinguals were affected more by interference in their native tongue (Treisman, 1964; Van Engen \& Bradlow, 2007).

Such an outcome suggests that bilingual speakers were better able to inhibit the interfering sentences. When there was a close match in terms of proficiency in the target language (Italian) this yielded a bilingual advantage. In contrast, there was no overall advantage for bilingual 
relative to monolingual English speakers nor, perhaps surprisingly, any disadvantage. Our bilingual sample varied in their English proficiency. On the supposition that their English proficiency is a proxy for experience in using a language and in controlling its use in competition with the other language (they lived in London and used both English and Italian), we looked to see if the more proficient showed less interference. Indeed, we found that more proficient English speakers showed less interference: they were not only more accurate than less proficient speakers when responding to non-canonical English sentences in the face of Italian interference but also when comprehending Italian non-canonical sentences in the face of Italian interference.

Experience in language control may, then, be crucial to any bilingual advantage in moderating the effects of sentence-level interference during the comprehension of both native and non-native languages.

Our data help resolve an apparent discrepancy in the literature. Typically bilinguals are disadvantaged relative to monolinguals in understanding auditorilypresented sentences when they are degraded by noise or reverberation (Mayo et al., 2007; Shi, 2010). We found no such disadvantage in our paradigm. The most likely reason is, we suggest, that our task allowed participants to use a consistent signal, namely the speaker's voice, to identify the interference sentence. In these circumstances, bilinguals may compensate through their greater facility in controlling interference.

We have urged an interpretation of these data in terms of the control of interference. Our bilingual participants live and work in London and so use and listen to Italian and English in everyday contexts. We suggest that such experience (in both speech and comprehension) enhances skills in controlling interference. We consider (i) whether or not there is a simpler account, and (ii) whether these data speak to the locus of control.

Perhaps our bilingual speakers are simply better at selecting the target sentence on the basis of a voice cue at an early stage in speech processing. We cannot rule out this possibility despite the equivalent performance of the bilingual and monolingual groups on the auditorymotor task. But if the bilingual speakers were better at selecting the target sentence on the basis of the voice cue, this fact would not be sufficient to explain our data. It cannot explain why interference is greater for non-canonical sentences. Selection by voice at an early stage of processing predicts comparable effects for canonical and non-canonical sentences relative to the no-interference baseline. Of course, using voice to select the relevant target sentence is crucial but, as our data indicate, the control interference makes use of a resource involved in sentence interpretation (as indicated by the interaction between interference and canonicity). As the task requires participants to identify the agent of the sentence, one possible locus of interference is at the stage of assigning thematic roles. Individuals in the task must identify the agent on the basis of potentially competing cues (e.g., sentence position vs. syntactic role). An interfering sentence increases competition that is more difficult to resolve when the comprehension demands are high. On this view, bilinguals are better able to resist such interference.

An alternative possibility is that bilingual speakers are simply more effective in using syntactic cues to identify the agent. However, such a processing advantage could not be deployed effectively without controlling interference. We infer, then, that differences in the ability to control interference is a necessary component in any full explanation of our data. However further work is needed to identify the precise locus of such control. If, as we are suggesting, it is at the stage of thematic assignment (i.e., constructing a representation of the meaning of the target sentence), much weaker effects will be observed if the interfering material does not compete in this fashion (e.g., a list of adjectives). If, on the other hand, the bilingual advantage in this task arises because of superior skill at reducing lexical interference per se (as in the Stroop task, Bialystok et al., 2008) then the same result will obtain with interfering verbal material that is not sentence-like.

In conclusion, our data extend evidence for a bilingual advantage in verbal control beyond the syllable level (Soveri et al., 2011) and word-level (e.g., Bialystok et al., 2008) to the level of sentence interpretation. There may indeed be different loci of control (e.g., Abutalebi \& Green, 2007; Kroll, Bobb \& Wodniecka, 2006). Our work suggests that control can be exerted at the level of thematic assignment but does not rule out a lexical locus.

The effects observed here were obtained with late bilinguals, immersed in a second-language environment and using and listening to both languages in their daily lives. It remains to be seen whether such effects generalise to other bilingual speakers. Most crucially, our work, along with other studies examining issues to do with language control, needs to be complemented by longitudinal research in order to examine within the individual the relationship between proficiency in a second language and effective cognitive control.

\section{Appendix. List of stimuli used in the sentence interpretation task}

English sentences were adapted from the Leech et al. (2007) study and translated into Italian. Sentences were split into two categories, canonical (actives and subject clefts) and non-canonical (passives and object clefts).

\section{CAMBridge JDURNALS}




\begin{tabular}{ll}
\hline \hline & \multicolumn{1}{c}{ Actives (Canonical S-V-O) } \\
\hline & \multicolumn{1}{c}{ English } \\
& Il Pappagallo Morde il Toro \\
The Parrot is Biting the Bull & La Capra Insegue il Serpente \\
The Goat is Chasing the Snake & Il Gatto Mangia l'Aquila \\
The Cat is Eating the Eagle & La Volpe Afferra la Foca \\
The Fox is Grabbing the Seal & Il Cavallo Colpisce il Lupo \\
The Horse is Bumping the Bull & La Balena Ferisce il Cane \\
The Whale is Hurting the Dog & I Gatti Calciano le Foche \\
The Cats are Kicking the Seals & Le Volpi Tirano le Scimmie \\
The Foxes are Pulling the Monkeys & I Cani Spingono i Cavalli \\
The Dogs are Pushing the Horses & Le Capre Graffiano i Lupi \\
The Goats are Scratching the Snakes & I Maiali Spaventano le Aquile \\
The Pigs are Scaring the Eagles & Le Balene Picchiano le Rane \\
The Whales are Hitting the Frogs & Il Toro Morde i Gatti \\
The Bull is Biting the Cats & La Foca Insegue i Maiali \\
The Seal is Chasing the Pigs & Il Serpente Mangia le Capre \\
The Snake is Eating the Goats & L'Aquila Afferra le Volpi \\
The Eagle is Grabbing the Foxes & Il Lupo Colpisce i Pappagalli \\
The Wolf is Bumping the Parrots & La Mucca Ferisce le Balene \\
The Cow is Hurting the Whales & I Tori Calciano la Capra \\
The Bulls are Kicking the Goat & Le Foche Tirano la Balena \\
The Seals are Pulling the Whale & I Serpenti Spingono il Maiale \\
The Snakes are Pushing the Pig & Le Rane Graffiano il Pappagallo \\
The Frogs are Scratching the Parrot & I Pappagalli Spaventano la Scimmia \\
The Horses are Scaring the Monkey & Le Aquile Picchiano la Rana \\
The Eagles are Hitting the Frog & \\
\hline &
\end{tabular}

\begin{tabular}{|c|c|}
\hline \multicolumn{2}{|c|}{ Subject clefts (Canonical S-V-O) } \\
\hline English & Italian \\
\hline It's the Pig that is Kicking the Whale & É il Maiale che Calcia la Balena \\
\hline It's the Monkey that is Pulling the Fox & É la Scimmia che Tira la Volpe \\
\hline It's the Cat that is Pushing the Pig & É il Gatto che Spinge il Maiale \\
\hline It's the Fox that is Scratching the Cat & É la Volpe che Graffia il Gatto \\
\hline It's the Horse that is Scaring the Monkey & É il Cavallo che Spaventa la Scimmia \\
\hline It's the Goat that is Hitting the Frog & É la Capra che Picchia la Rana \\
\hline It's the Bulls that are Kicking the Seals & Sono i Tori che Calciano le Foche \\
\hline It's the Eagles that are Pulling the Monkeys & Sono le Aquile che Tirano le Scimmie \\
\hline It's the Snakes that are Pushing the Horses & Sono i Serpenti che Spingono i Cavalli \\
\hline It's the Frogs that are Scratching the Pigs & Sono le Rane che Graffiano i Maiali \\
\hline It's the Horses that are Scaring the Whales & Sono i Cavalli che Spaventano le Balene \\
\hline It's the Seals that are Hitting the Frogs & Sono le Foche che Picchiano le Rane \\
\hline It's the Dog that is Biting the Parrots & É il Cane che Morde i Pappagalli \\
\hline It's the Seal that is Chasing the Snakes & É la Foca che Insegue i Serpenti \\
\hline It's the Wolf that is Eating the Cows & É il Lupo che Mangia le Mucche \\
\hline It's the Whale that is Grabbing the Monkeys & É la Balena che Afferra le Scimmie \\
\hline It's the Bull that is Bumping the Wolves & É il Toro che Colpisce i Lupi \\
\hline It's the Cow that is Hurting the Dogs & É la Mucca che Ferisce i Cani \\
\hline It's the Cats that are Biting the Horse & Sono i Gatti che Mordono il Cavallo \\
\hline
\end{tabular}

\section{CAMBRIDGE JDURALS}


It's the Whales that are Chasing the Snake It's the Dogs that are Eating the Eagle It's the Goats that are Grabbing the Seal It's the Pigs that are Bumping the Bull It's the Monkeys that are Hurting the Wolf
Sono le Balene che Inseguono il Serpente

Sono i Cani che Mangiano l'Aquila

Sono le Capre che Afferrano la Foca

Sono i Maiali che Colpiscono il Toro

Sono le Scimmie che Feriscono il Lupo

\begin{tabular}{|c|c|}
\hline \multicolumn{2}{|c|}{ Passives (Non-canonical O-V-S) } \\
\hline English & Italian \\
\hline The Dog is Kicked by the Frog & Il Cane é Calciato dalla Rana \\
\hline The Seal is Pulled by the Fox & La Foca é Tirata dalla Volpe \\
\hline The Snake is Pushed by the Parrot & Il Serpente é Spinto dal Pappagallo \\
\hline The Eagle is Scratched by the Cat & L’Aquila é Graffiata dal Gatto \\
\hline The Bull is Scared by the Monkey & Il Toro é Spaventato dalla Scimmia \\
\hline The Frog is Hit by the Cow & La Rana é Picchiata dalla Mucca \\
\hline The Cats are Bitten by the Bulls & I Gatti sono Morsi dai Tori \\
\hline The Foxes are Chased by the Pigs & Le Volpi sono Inseguite dai Maiali \\
\hline The Dogs are Eaten by the Seals & I Cani sono Mangiati dalle Foche \\
\hline The Goats are Grabbed by the Foxes & Le Capre sono Afferrati dalle Volpi \\
\hline The Pigs are Bumped by the Parrots & I Maiali sono Colpiti dai Pappagalli \\
\hline The Monkeys are Hurt by the Dogs & Le Scimmie sono Feriti dai Cani \\
\hline The Pig is Kicked by the Goats & Il Maiale é Calciato dalle Capre \\
\hline The Goat is Pulled by the Monkeys & La Capra é Tirata dalle Scimmie \\
\hline The Wolf is Pushed by the Horses & Il Lupo é Spinto dai Cavalli \\
\hline The Fox is Scratched by the Snakes & La Volpe é Graffiata dai Serpenti \\
\hline The Horse is Scared by the Eagles & Il Cavallo é Spaventato dalle Aquile \\
\hline The Monkey is Hit by the Frogs & La Scimmia é Picchiata dalle Rane \\
\hline The Bulls are Bitten by the Horse & I Tori sono Morsi dal Cavallo \\
\hline The Cows are Chased by the Snake & Le Mucche sono Inseguite dal Serpente \\
\hline The Parrots are Eaten by the Eagle & I Pappagalli sono Mangiati dall'Aquila \\
\hline The Frogs are Grabbed by the Seal & Le Rane sono Afferrate dalla Foca \\
\hline The Wolves are Bumped by the Pig & I Lupi sono Colpiti dal Maiale \\
\hline The Eagles are Hurt by the Dog & Le Aquile sono Ferite dal Cane \\
\hline
\end{tabular}

\begin{tabular}{|c|c|}
\hline \multicolumn{2}{|c|}{ Object Clefts (Non-canonical O-S-V) } \\
\hline English & Italian \\
\hline It's the Pig that the Horse is Biting & É il Maiale che il Cavallo Morde \\
\hline It's the Seal that the Parrot is Chasing & É la Foca che il Pappagallo Insegue \\
\hline It's the Snake that the Eagle is Eating & É il Serpente che l'Aquila Mangia \\
\hline It's the Frog that the Goat is Grabbing & É la Rana che la Capra Afferra \\
\hline It's the Parrot that the Horse is Bumping & É il Pappagallo che il Cavallo Colpisce \\
\hline It's the Eagle that the Wolf is Hurting & É l’Aquila che il Lupo Ferisce \\
\hline It's the Cats that the Wolves are Biting & Sono i Gatti che i Lupi Mordono \\
\hline It's the Monkeys that the Parrots are Chasing & Sono le Scimmie che i Pappagalli Inseguono \\
\hline It's the Dogs that the Goats are Eating & Sono i Cani che le Capre Mangiano \\
\hline It's the Whales that the Foxes are Grabbing & Sono le Balene che le Volpi Afferrano \\
\hline It's the Pigs that the Cats are Bumping & Sono i Maiali che i Gatti Colpiscono \\
\hline It's the Whales that the Pigs are Hurting & Sono le Balene che i Maiali Feriscono \\
\hline
\end{tabular}

\section{CAMBRIDGE JDURNALS}


It's the Pig that the Seals are Kicking It's the Cow that the Monkeys are Pulling It's the Dog that the Bulls are Pushing It's the Cow that the Snakes are Scratching It's the Horse that the Cows are Scaring It's the Frog that the Whales are Hitting It's the Bulls that the Monkey is Kicking It's the Seals that the Cow is Pulling It's the Horses that the Bull is Pushing It's the Frogs that the Cat is Scratching It's the Bulls that the Whales are Scaring It's the Cows that the Frog is Hitting
É il Maiale che le Foche Calciano

É la Mucca che le Volpi Tirano

É il Cane che i Tori Spingono

É la Mucca che i Serpenti Graffiano

É il Cavallo che le Mucche Spaventano

E' la Rana che le Balene Picchiano

Sono i Lupi che la Scimmia Calcia

Sono le Foche che la Mucca Tira

Sono i Cavalli che il Toro Spinge

Sono le Rane che il Gatto Graffia

Sono i Tori che la Balena Spaventa

Sono le Mucche che la Rana Picchia

\section{References}

Abbate, M. S., \& LaChapelle, N. B. (1984a). Pictures, please! A language supplement. Tucson, AZ: Communication Skill Builders, Inc.

Abbate, M. S., \& LaChapelle, N. B. (1984b). Pictures, please! An articulation supplement. Tucson, AZ: Communication Skill Builders, Inc.

Abutalebi, J., \& Green, D. W. (2007). Bilingual language production: The neurocognition of language representation and control. Journal of Neurolinguistics, 20, 242-275.

Bates, E., Devescovi, A., \& Wulfeck, B. (2001). Psycholinguistics: A cross-language perspective. Annual Review of Psychology, 52, 369-398.

Bates, E., McNew, S., MacWhinney, B., Devescovi, A., \& Smith, S. (1982).Functional constraints on sentence processing: A cross-linguistic study. Cognition, 11, 245-299.

Bialystok, E. (1988). Levels of bilingualism and levels of linguistic awareness. Developmental Psychology, 24, 560567.

Bialystok, E. (1999). Cognitive complexity and attentional control in the bilingual mind. Child Development, 70, 636644.

Bialystok, E. (2009). Bilingualism: The good, the bad, and the indifferent. Bilingualism: Language and Cognition, 12, 311 .

Bialystok, E., Craik, F. I. M., Green, D. W., \& Gollan, T. H. (2009). Bilingual minds. Psychological Science in the Public Interest, 10, 89-129.

Bialystok, E., Craik, F. I. M., Klein, R., \& Viswanathan, M. (2004). Bilingualism, aging, and cognitive control: Evidence from the Simon task. Psychology and Aging, 19, 290-303.

Bialystok, E., Craik, F. I. M., \& Luk, G. (2008). Cognitive control and lexical access in younger and older bilinguals. Journal of Experimental Psychology: Learning, memory and Cognition, 34, 859-873.

Bialystok, E., Craik, F. I. M., \& Ryan, J. (2006). Executive control in a modified anti-saccade task: Effects of aging and bilingualism. Journal of Experimental Psychology: Learning, Memory, and Cognition, 32, 1341- 1354.

Bialystok, E., Martin, M. M., \& Viswanathan, M. (2005). Bilingualism, across the lifetime: The rise and fall of inhibitory control. International Journal of Bilingualism, 9, 103-119
Bilger, R. C., Nuetzel, J. M., Rabinowitz, W. M., \& Rzeczkowski, C. (1984). Standardization of a test of speech perception in noise. Journal of Speech and Hearing Research, 27, 32-48.

Boersma, P., \& Weenink, D. (2010). Praat: Doing phonetics by computer (computer program), version 5.1.38. http://www.praat.org/ (retrieved July 2, 2010).

Carlson, S. M., \& Meltzoff, A. N. (2008). Bilingual experience and executive functioning in young children. Developmental Science, 11, 282-298.

Costa, A., \& Caramazza, A. (1999). Is lexical selection in bilingual speech production language-specific? Further evidence from Spanish-English and English-Spanish bilinguals. Bilingualism: Language and Cognition, 2, 231244.

Costa, A., Hernandez, M., \& Sebastián-Gallés, N. (2008). Bilingualism aids conflict resolution: Evidence from the ANT task. Cognition, 106, 59-86.

Dick, F., Wulfeck, B., Aydelott, J. A., Dronkers, N., Gernsbacher, M. A., \& Bates, E. (2001). Language deficits, localization, and grammar: Evidence for a distributive model of language breakdown in aphasic patients and neurologically intact individuals. Psychological Review, 108, 759-788.

Dijkstra, T., Van Jaarsveld, H., \& Brinke, S. (1998). Interlingual homograph recognition: Effects of task demands and language intermixing. Bilingualism: Language and Cognition, 1, 51-66.

Finkbeiner, M., Gollan, T., \& Caramazza, A. (2006). Bilingual lexical access: What's the (hard) problem? Bilingualism: Language and Cognition, 9, 153-166.

Green, D. W. (1986). Control, activation, and resource: A framework and a model for the control of speech in bilinguals. Brain and Language, 27, 210-223.

Green, D. W. (1998). Mental control of the bilingual lexicosemantic system. Bilingualism: Language and Cognition, 1, 67-81.

Hoshino, N., \& Thierry, G. (2011). Language selection in bilingual word production: Electrophysiological evidence for cross-language competition. Brain Research, 1371, $100-109$.

Hugdahl, K., \& Andersson, L. (1986). The "forced-attention paradigm" in dichotic listening to syllables: A comparison between adults and children. Cortex, 22, 417-432.

Kalikow, D. N., Stevens, K. N., \& Elliot, L. L. (1977). Development of a test of speech intelligibility in noise using

\section{CAMBrIDGE JURNALS}


sentence materials with controlled word predictability. Journal of the Acoustical Society of America, 61, 13371351.

Kroll, J. F., Bobb, S. C., \& Wodniecka, Z. (2006). Language selectivity is the exception, not the rule: Arguments against a fixed locus of language selection in bilingual speech. Bilingualism: Language and Cognition, 9, 119 135.

Leech, R., Aydelott, J., Symons, G., Carnevale, J., \& Dick, F. (2007). The development of sentence interpretation: Effects of perceptual, attentional and semantic interference. Developmental Science, 10 (6), 794-813.

Li, P., Sepanski, S., \& Zhao, X. (2006). Lanuage history questionnaire: A web-based interface for bilingual research. Behaviour research Methods, 38 (2), 202 210.

Linck, J. A., Kroll, J. F., \& Sunderman, G. (2009). Losing access to the native language while immersed in a second language. Psychological Science, 20, 1507-1515.

Macizo, P., Bajo, T., \& Cruz Martin, M. (2010). Inhibitory processes in bilingual language comprehension: Evidence from Spanish-English interlexical homographs. Journal of Memory and Language, 63, 232-244.

MacWhinney, B., \& Bates, E. (1989). Cross-linguistic study of sentence processing. New York: Cambridge University Press.

Martin-Rhee, M. M., \& Bialystok, E. (2008). The development of two types of inhibitory control in monolingual and bilingual children. Bilingualism: Language and Cognition, 11, 1-13.

Mayo, L. H., Florentine, M., \& Buus, S. (1997). Age of sencond language acquisition and perception of speech in noise. Journal of Speech, Language and Hearing Research, 40, 686-693.

Muñoz-Sandoval, A. F., Cummins, J., Alvarado, C. G., \& Ruef, M. L. (1998). Bilingual Verbal Ability Tests: Comprehensive manual. Itasca, IL: Riverside.

Philipp, A. M., \& Koch, I. (2009). Inhibition in language switching: What is inhibited when switching between languages in naming tasks? Journal of Experimental Psychology: Learning, Memory, and Cognition, 35, 11871195.

Prior, A., \& MacWhinney, B. (2010). A bilingual advantage in task switching. Bilingualism: Language and Cognition, 13, 253-262.

Raven, J. C. (1947). Progressive matrices. London: Lewis.

Rogers, C. L., Lister, J. J., Febo, D. M., Besing, J. L., \& Abrams, H. B. (2006). Effect of bilingualism, noise, and reverberation on speech perception by listeners with normal hearing. Applied Psycholinguistics, 27, 465-485.
Roland, D., Dick, F., \& Elman, J. L. (2007). Frequency of basic English grammatical structures: A corpus analysis. Journal of Memory and Language, 57, 348-379.

Shi, L. F. (2010). Perception of acoustically degraded Sentences in bilingual listeners who differ in age of English acquisition. Journal of Speech, Language and Hearing Research, 53, 821-835.

Snodgrass, J. G., \& Vanderwart, M. (1980). A standardized set of 260 pictures: Norms for name agreement, familiarity and visual complexity. Journal of Experimental Psychology: Human Learning and Memory, 10, 174-215.

Snyder, H. R., Hutchison, N., Nyhus, E., Curran, T., Banich, M. T., O'Reilly, R. C., \& Munakata, Y. (2010). Neural inhibition enables selection during language processing. Proceedings of the National Academy of Sciences, 107, 16483-16488.

Soveri, A., Laine, M., Hämäläinen, H., \& Hugdah, K. (2011). Bilingual advantage in attentional control: Evidence from the forced-attention dichotic listening paradigm. Bilingualism: Language and Cognition, 14, 371-378.

Tabri, D., Chacra, K. M. S. A., \& Pring, T. (2011). Speech perception in noise by monolingual, bilingual, and trilingual listeners. International Journal of Language Communication Disorders, 46, 411-422.

Treisman, A. M. (1964). Verbal cues, Language, and meaning in selective attention. The American Journal of Psychology, 77, 206-219.

Tzelgov, J., Henik, A., \& Leiser, D. (1990). Controlling Stroop interference: Evidence from a bilingual task. Journal of Experimental Psychology: Learning, Memory, and Cognition, 16, 760-771.

Van Engen, K. J., \& Bradlow, A. R. (2007). Sentence recognition in native and foreign language multi-talker background noise. Journal of Acoustical Society of America, 121, 519 526.

Van Hell, J. G., \& Dijkstra, T. (2002). Foreign language knowledge can influence native language performance in exclusively native contexts. Psychonomic Bulletin and Review, 9, 780-789.

Von Studnitz, R. E., \& Green, D. W. (2002). Interlingual homograph interference in German-English bilinguals: Its modulation and locus of control. Bilingualism: Language and Cognition, 5, 1-23.

Yang, S., Yang, H., \& Lust, B. (2011). Early childhood bilingualism leads to advances in executive attention: Dissociating culture and language. Bilingualism: Language and Cognition, 14 (3), 412-422.

Wu, Y. J., \& Thierry, G. (2010). Chinese-English bilinguals reading English hear Chinese. Journal of Neuroscience, 30, 7646-7651. 